\title{
Boulder-Faced Log Dams and other Alternatives for Gabion Check Dams in First-Order Ephemeral Streams with Coarse Bed Load in Ethiopia
}

\author{
Jan Nyssen (1), Seifu Gebreslassie (2,3), Romha Assefa (4,5), Jozef Deckers (6), Etefa Guyassa $(1,7)$, Jean \\ Poesen (6), and Amaury Frankl (1) \\ (1) Department of Geography, Ghent University, Gent, Belgium (jan.nyssen@ugent.be), (2) Previously at Selam-Watsani \\ Project, Dogu'a Tembien, Tigray, Ethiopia, (3) Current address: EthioTrees Project, Dogu'a Tembien, Tigray, Ethiopia, (4) \\ Previously at Ma'ar Project, Dogu'a Tembien, Tigray, Ethiopia, (5) Current address: Relief Society of Tigray, Mekelle, \\ Ethiopia, (6) Department of Earth and Environmental Sciences, KULeuven, Leuven, Belgium, (7) Department of Land \\ Resources Management and Environmental Protection, Mekelle University, Mekelle, Ethiopia
}

Many thousands of gabion check dams have been installed to control gully erosion in Ethiopia, but several challenges still remain, such as the issue of gabion failure in ephemeral streams with coarse bed load, that abrades at the chute step. As an alternative for gabion check dams in torrents with coarse bed load, boulder-faced log dams were conceived, installed transversally across torrents and tested $(\mathrm{n}=30)$. For this, $\operatorname{logs}(22-35 \mathrm{~cm}$ across $)$ were embedded in the banks of torrents, $0.5-1 \mathrm{~m}$ above the bed and their upstream sides were faced with boulders $(0.3$ $0.7 \mathrm{~m}$ across). Similar to gabion check dams, boulder-faced log dams lead to temporary ponding, spreading of peak flow over the entire channel width and sediment deposition. Results of testing under extreme flow conditions (including two storms with return periods of 5.6 and 7 years) show that 18 dams resisted strong floods. Beyond certain flood thresholds, represented by proxies such as Strahler's stream order, catchment area, D95 or channel width), $11 \mathrm{log}$ dams were completely destroyed. Smallholder farmers see much potential in this type of structure to control first-order torrents with coarse bed load, since the technique is cost-effective and can be easily installed. 